Check for updates

Cite this: RSC Adv., 2019, 9, 10976

Received 25th January 2019

Accepted 1st April 2019

DOI: $10.1039 / c 9 r a 00683 d$

rsc.li/rsc-advances

\section{Nitrogen doped microporous carbon nanospheres derived from chitin nanogels as attractive materials for supercapacitors}

\author{
Si Zheng, Yin Cui, Jianwei Zhang, Yuxing Gu, Xiaowen Shi, DD* Chuang Peng* \\ and Dihua Wang iD
}

$\mathrm{N}$-doped porous carbon nanospheres were fabricated directly by pyrolyzing chitin nanogels, which were facilely prepared by mechanical agitation induced sol-gel transition of chitin solution in $\mathrm{NaOH} / \mathrm{urea}$ solvent. The resulting carbon nanospheres displayed ordered micropores (centered at $\sim 0.6 \mathrm{~nm}$ ) and high BET surface area of up to $1363 \mathrm{~m}^{2} \mathrm{~g}^{-1}$, which is substantially larger than that of the carbons from raw chitin $\left(600 \mathrm{~m}^{2} \mathrm{~g}^{-1}\right)$. In addition, the carbon nanospheres retained a nitrogen content of $3.2 \%$ and excellent conductivity. Consequently, supercapacitor electrodes prepared from the carbon nanospheres pyrolyzed at $800{ }^{\circ} \mathrm{C}$ showed a specific capacitance as high as $192 \mathrm{~F} \mathrm{~g}^{-1}$ at a current density of $0.5 \mathrm{~A} \mathrm{~g}^{-1}$ and impressive rate capability $\left(81 \%\right.$ retention at $\left.10 \mathrm{~A} \mathrm{~g}^{-1}\right)$. When assembled in a symmetrical twoelectrode cell, $\mathrm{N}$-doped porous carbon nanospheres demonstrated excellent cycling stability both in aqueous and organic electrolytes (95\% retention after 10000 cycles at $10 \mathrm{~A} \mathrm{~g}^{-1}$ ), together with outstanding energy density of $5.1 \mathrm{~W} \mathrm{~h} \mathrm{~kg}^{-1}$ at the power density of $2364.9 \mathrm{~W} \mathrm{~kg}^{-1}$. This work introduces a novel and efficient method to prepared $\mathrm{N}$-doped porous carbon nanospheres directly from chitin and demonstrates the great potential of utilization of abundant polymers from nature in power storage.

\section{Introduction}

Carbon materials are promising candidates for supercapacitor electrodes due to their low cost, good conductivity, abundance and long cycle life. ${ }^{1}$ The development of carbon materials with a hierarchical porous structure, which facilitates electrolyte-ion transfer and provides a shorter diffusion pathway, is essential for the fabrication of advanced electric double-layer capacitors. $^{2-4}$ Biomass wastes are attractive renewable resources for porous carbon preparation (leaves, ${ }^{5}$ beans shells,${ }^{6}$ cuttlebones, ${ }^{7}$ wood, ${ }^{8}$ etc.). So far, a variety of carbon materials with tailored porous structures have been prepared from natural precursors, such as protein, ${ }^{9}$ cellulose ${ }^{10-13}$ alginate ${ }^{14,15}$ and chitin. ${ }^{16-20}$ Among them, porous carbon from chitin has attracted special attention due to its high nitrogen content, allowing direct fabrication of N-enriched carbon without additional nitrogen sources. The faradaic reactions between nitrogen and electrolyte contribute pseudocapacitance, which could substantially improve the performance of the supercapacitor.

Chitin is mainly extracted from aquatic biomass waste such as the shells of shrimp and crab. It is $\beta$-(1-4)-linked 2-acetamido-

School of Resource and Environmental Science, Hubei International Scientific and Technological Cooperation Base of Sustainable Resource and Energy, Hubei Biomass-Resource Chemistry and Environmental Biotechnology Key Laboratory, Wuhan University, Wuhan 430079, China. E-mail: Shixw@whu.edu.cn; Chuang. peng@whu.edu.cn
2-deoxy-D-glucopyranose with a nitrogen amount of $6.9 \mathrm{wt} \%$. Ndoped porous carbon can be facilely obtained by pyrolyzing chitin and has been developed for high-performance capacitor. $^{21}$ However, direct carbonization of bulk chitin does not offer sufficient control over porosity and microstructure. Recently, chitin microspheres, ${ }^{19,22}$ nanofibers and aerogels ${ }^{18,20}$ were selected as precursors for $\mathrm{N}$-doped carbon, which demonstrated large surface area, hierarchical porosity and high electrochemical performance. Importantly, chitin derived carbon showed favorable retention of morphology after pyrolyzation due to the stiffness of chitin chains. ${ }^{19}$ Therefore, a preformed chitin precursor with well define nanostructure provides great opportunities for new nanocarbon materials.

Recent work revealed the advantages of carbon nanospheres $^{23-25}$ as high performance supercapacitor electrode when applied in supercapacitors. ${ }^{26,27}$ Particularly, carbon nanospheres with hierarchical porous architectures demonstrated maximized specific surface area while minimized electron and ion transport distances. ${ }^{28}$ The methodology to prepare carbon nanospheres generally includes either a hard-template method or a soft template method. ${ }^{28-30}$ Organic polymers ${ }^{29,31,32}$ and silica $^{33,34}$ were commonly used for the fabrication of carbon nanospheres. Direct carbonization of preformed natural polymeric nanoparticles provides a facile and environmentally friendly method for the preparation of carbon nanospheres, though few reports have been devoted to this effort. 
Herein, we report the preparation of carbon nanospheres directly from chitin nanogels for the first time. Chitin nanogels with a diameter of $20-30 \mathrm{~nm}$ were prepared by a mechanical agitation induced sol-gel transition method with high efficiency. Interconnected porous framework of N-doped carbon nanospheres (nitrogen content of 3.2\%) was obtained by directly pyrolyzing the chitin nanogels. The as-prepared typical carbon had a high BET surface area (up to $1363 \mathrm{~m}^{2} \mathrm{~g}^{-1}$ ) and a regular micropore peaked at $0.6 \mathrm{~nm}$, which benefit the fast transportation and diffusion of electrolyte ions. When used for supercapacitor, the carbon nanospheres showed a specific capacitance of $192 \mathrm{~F} \mathrm{~g}^{-1}$ at $0.5 \mathrm{~A} \mathrm{~g}^{-1}$ in $1 \mathrm{M} \mathrm{H}_{2} \mathrm{SO}_{4}$ electrolyte. Besides, the chitin nanospheres could be used in organic electrolyte, demonstrating a specific capacitance of $107 \mathrm{~F} \mathrm{~g}^{-1}$ at $1.0 \mathrm{~A} \mathrm{~g}^{-1}$ in $\mathrm{TEABF}_{4}$-AN electrolyte and an excellent cycling stability, with a capacitance retention of $95 \%$ after 10000 cycles at $10 \mathrm{~A} \mathrm{~g}^{-1}$. The present study provides a simple and highly efficient route to fabricate $\mathrm{N}$-doped carbon nanospheres from chitin and highlights the great potential of well-structured carbon nanospheres derived from chitin for high-performance supercapacitors.

\section{Experimental}

\section{Materials}

The raw chitin power was purchased from Yun-Zhou Biochemical Co. Ltd. (Shandong, China). Tetraethylammonium tetrafluoroborate salt $\left(\mathrm{TEABF}_{4}\right)$, polytetrafluoroethylene (PTFE) (60 wt\% dispersion in ethanol), acetylene black were purchased from Aladdin Reagent Co. Ltd. The titanium mesh was supplied by Gaoss Union Co. Ltd. All of the chemical reagents were of analytical grade and used without further purification.

\section{Preparation of chitin nanogels}

According to previously reported method, ${ }^{35}$ the purchased chitin was purified by treating with $5 \mathrm{wt} \% \mathrm{NaOH}$ aqueous solution, $7 \%(\mathrm{v} / \mathrm{v}) \mathrm{HCl}$ aqueous solution and $1.7 \mathrm{wt} \% \mathrm{NaClO}_{2}$ in $0.3 \mathrm{M} \mathrm{CH}_{3} \mathrm{COONa}$ buffer to remove impurities such as the protein, mineral and pigments. Purified chitin powder $(2 \mathrm{~g})$ was dispersed in a solvent of $\mathrm{NaOH}$, urea, and distilled water $(98 \mathrm{~g}$, weight ratio $8: 4: 88$ ). Subsequently, the mixed suspension was refrigerated at $-30^{\circ} \mathrm{C}$ for $4 \mathrm{~h}$, later thawed at room temperature. After two freezing-thawing cycles, a transparent chitin solution was obtained. ${ }^{36}$ The chitin solution was stirred with a homogenizer to form a milky dispersion. Then the dispersion was dialyzed against deionized water to remove residual inorganic salts. After that the chitin nanogels dispersion was obtained. The resulted chitin nanogels were pre-frozen in liquid nitrogen and then dried in a freeze dryer to get the precursor.

\section{Preparation of carbon nanospheres}

The resulted chitin nanogels were carbonized under $800{ }^{\circ} \mathrm{C}$ or $900{ }^{\circ} \mathrm{C}$ for $2 \mathrm{~h}$, under an $\mathrm{Ar}$ atmosphere with a ramp rate of $3{ }^{\circ} \mathrm{C} \min ^{-1}$ in a tubular furnace. The obtained products were coded as CNC-800 and CNC-900, respectively.

\section{Material characterization}

Surface morphology of the samples was observed by field emission scanning electron microscope (FE-SEM, Zeiss, SIGMA) under an accelerating voltage of $5 \mathrm{kV}$, high resolution transmission electron microscope (HR-TEM, JEM-2100) under an acceleration voltage of $200 \mathrm{kV}$ and atomic force microscope (AFM, Cypher ES, Asylum Research) in AC mode at $25{ }^{\circ} \mathrm{C}$. Crystallographic structure was measured on an X-ray diffraction system (XPert Pro) with $\mathrm{Cu} \mathrm{K} \alpha$ radiation $(\lambda=0.15406 \mathrm{~nm})$ at 40 $\mathrm{kV}$ and $40 \mathrm{~mA}$, and the data was collected in the $2 \theta$ range of $10-$ $80^{\circ}$. Raman spectrum was employed by confocal Raman microspectroscopy (Renishaw, RM-1000) at an excitation wavelength of $514.5 \mathrm{~nm}$ from $\mathrm{Ar}^{+}$laser. The surface chemistry analysis was conducted by X-ray photoelectron spectrometer (Thermo Fisher Scientific, ESCALAB250Xi) with monochromatic Al $\mathrm{K} \alpha$ radiation. The $\mathrm{N}_{2}$ adsorption/desorption measurement was performed on an automatic surface area analyzer (Micromeritics, ASAP-2460, USA) at $77 \mathrm{~K}$. Before the experiment, the samples were degassed at $150{ }^{\circ} \mathrm{C}$ for $12 \mathrm{~h}$ under vacuum to remove certain adsorbed species. The specific surface area and pore size distribution were analyzed through the BrunauerEmmett-Teller (BET) method and Density Functional Theory (DFT) model.

\section{Electrochemical measurements}

The electrochemical measurements were performed on an Autolab PGSTAT302N at room temperature. In a three-electrode cell, a platinum plate acted as the counter electrode, and a saturated calomel electrode (SCE) acted as the reference electrode connecting by a Luggin capillary filled with saturated $\mathrm{KCl}$ solution. The working electrode was consisted of $80 \mathrm{wt} \%$ asprepared $\mathrm{N}$-doped carbon nanospheres, $10 \mathrm{wt} \%$ acetylene black and $10 \mathrm{wt} \%$ polytetrafluoroethylene (PTFE) dispersed in ethanol. The mixture was homogenized by ultrasound and dried until ethanol was evaporated to form viscous slurry, which was roll-pressed into a thin film on a roller machine. The film was cut into pieces of $1 \mathrm{~cm}^{2}$ surface area and the mass of each piece was around $2 \mathrm{mg}$. Then this film was pressed onto a titanium mesh current collector. Before measurements, the prepared electrode was immersed in $1 \mathrm{M} \mathrm{H}_{2} \mathrm{SO}_{4}$ aqueous electrolyte overnight. The cyclic voltammetry $(\mathrm{CV})$ was measured at different scan rates $\left(20-200 \mathrm{mV} \mathrm{s}^{-1}\right)$ with the potential window of -0.4 to $0.6 \mathrm{~V} v s$. SCE. The galvanostatic charge/discharge (GCD) test was carried out at various current densities (0.5$10 \mathrm{~A} \mathrm{~g}^{-1}$ ) in the potential range of -0.4 to $0.6 \mathrm{~V}$. The specific capacitance $\left(C, \mathrm{~F} \mathrm{~g}^{-1}\right)$ of the electrode material was calculated according to eqn (1) ${ }^{32}$ from GCD curve.

$$
C=\frac{I \Delta t}{m \Delta V}
$$

where $I$ is current (A); $\Delta t$ is the discharge time (s); $m$ represents the mass of the active material in an electrode (g); and $\Delta V$ is the discharge potential range $(\mathrm{V})$.

In addition, to further investigate the electrochemical performance, symmetrical two-electrode systems were installed in $1 \mathrm{M} \mathrm{H}_{2} \mathrm{SO}_{4}$ aqueous electrolyte and $1 \mathrm{M} \mathrm{TEABF}_{4}-\mathrm{AN}$ organic 
electrolyte, respectively. In aqueous electrolyte, CV and GCD were tested with the potential window of $0-1 \mathrm{~V}$. Electrochemical impedance spectroscopy (EIS) was recorded over a frequency range from $0.01 \mathrm{~Hz}$ to $100 \mathrm{kHz}$ with an alternating current voltage of $5 \mathrm{mV}$ amplitude. In organic electrolyte, the potential window increased to $0-2.5 \mathrm{~V}$. Under this condition, $\mathrm{CV}, \mathrm{GCD}$ and cycling stabilities measurements were conducted. The specific capacitance of the symmetric electrodes $\left(C_{\mathrm{s}}, \mathrm{F} \mathrm{g}^{-1}\right)$, the energy density $\left(E, \mathrm{~W} \mathrm{~h} \mathrm{~kg}{ }^{-1}\right)$ and power density $\left(P, \mathrm{~W} \mathrm{~kg}^{-1}\right)$ of the symmetrical electrode system were calculated as follows: ${ }^{37-39}$

$$
\begin{gathered}
C_{\mathrm{s}}=\frac{2 I \Delta t}{m \Delta V} \\
E=\frac{C_{\mathrm{s}} V^{2}}{2 \times 4 \times 3.6} \\
P=\frac{3600 \times E}{\Delta t}
\end{gathered}
$$

where $V$ is the cell operating voltage (excluding the IR drop).

\section{Results and discussion}

The preparation of chitin-derived carbon nanospheres includes the formation of chitin nanogels and its subsequent carbonization, as demonstrated in Fig. 1. Firstly, transparent chitin solution was obtained by dissolution of chitin powder in a solvent of $\mathrm{NaOH}$, urea, and distilled water (weight ratio $8: 4: 88$ ) through freezing-thawing cycles. ${ }^{36}$ The strong intermolecular hydrogen bonds were destroyed by $\mathrm{NaOH} /$ urea solvent and led to complete dissolution of chitin chains. Secondly, chitin nanogels were fabricated by mechanical agitation induced sol-gel transition. The chitin solution is unstable and sensitive to temperature increase. The sol-gel transition was induced by the in situ heat generated during high-speed stirring (10 $000 \mathrm{rpm})$. Thirdly, the resulted chitin nanogels were freeze-dried and carbonized for $2 \mathrm{~h}$ under an $\mathrm{Ar}$ atmosphere to obtain $\mathrm{N}$-doped carbon nanospheres. The dark carbon nanospheres calcined under $800{ }^{\circ} \mathrm{C}$ and $900{ }^{\circ} \mathrm{C}$ were coded as CNC-800 and CNC-900 and the yields of CNC-800 and CNC-900 were $31.1 \%$ and $15.2 \%$ respectively. By comparison, carbons were also obtained by calcination of raw chitin powder at $800{ }^{\circ} \mathrm{C}$ and $900{ }^{\circ} \mathrm{C}$, coded as chitin- 800 and chitin-900.

The morphology of chitin nanogels was firstly observed by TEM and AFM (Fig. 2a and b). Well shaped nanospheres with a diameter of 20-30 nm were clearly observed. Freeze drying of the chitin nanogels resulted in a porous sponge, which was

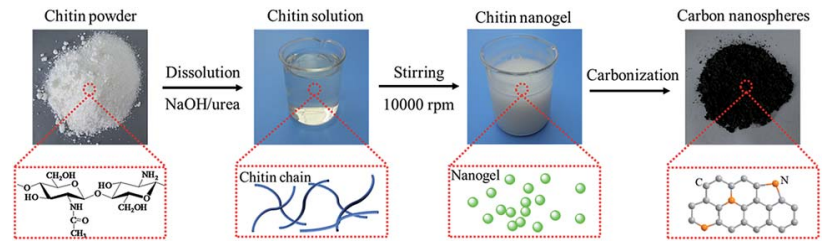

Fig. 1 Graphical representation of the formation process for chitinderived nanospheres.

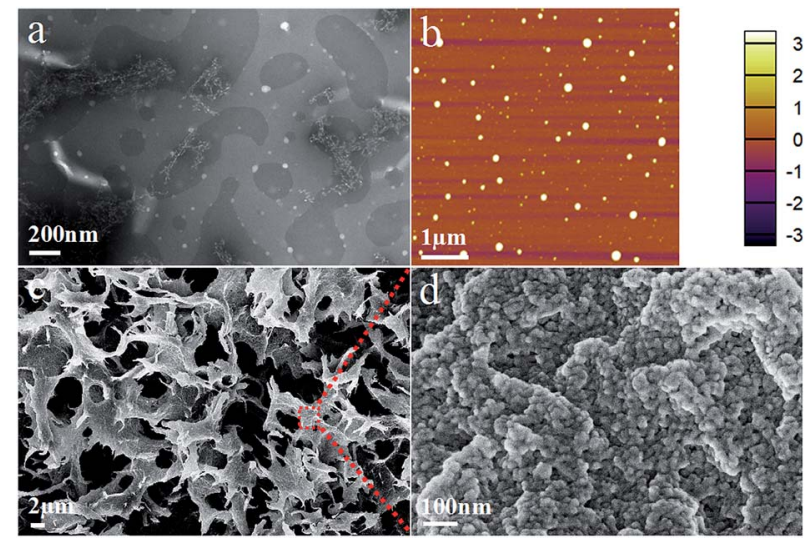

Fig. 2 Structural characterization of chitin nanogels: TEM image (a), AFM image (b) and SEM images ( $c$ and d).

further observed by SEM. The chitin sponge exhibited interconnected network with randomly opened pores (Fig. 2c) and the pore walls demonstrated a rough surface consisting of nanoparticles (Fig. 2d). N-doped carbon nanospheres were obtained by direct carbonization of the chitin nanogels. After carbonization, the original porous structure of the chitin nanogels was still maintained as shown by the low magnification images in Fig. 3a and c. The zoom in images demonstrated the carbon nanospheres were assembled into an interconnected framework and nanopores were clearly observed (Fig. 3b and d), especially in CNC-800. By comparison, the SEM images of raw chitin calcined at $800{ }^{\circ} \mathrm{C}$ (Fig. 3e) and $900{ }^{\circ} \mathrm{C}$ (Fig. 3f) demonstrated more compact structure. TEM and HRTEM images (Fig. 4) further confirmed the spherical morphology of CNC-800

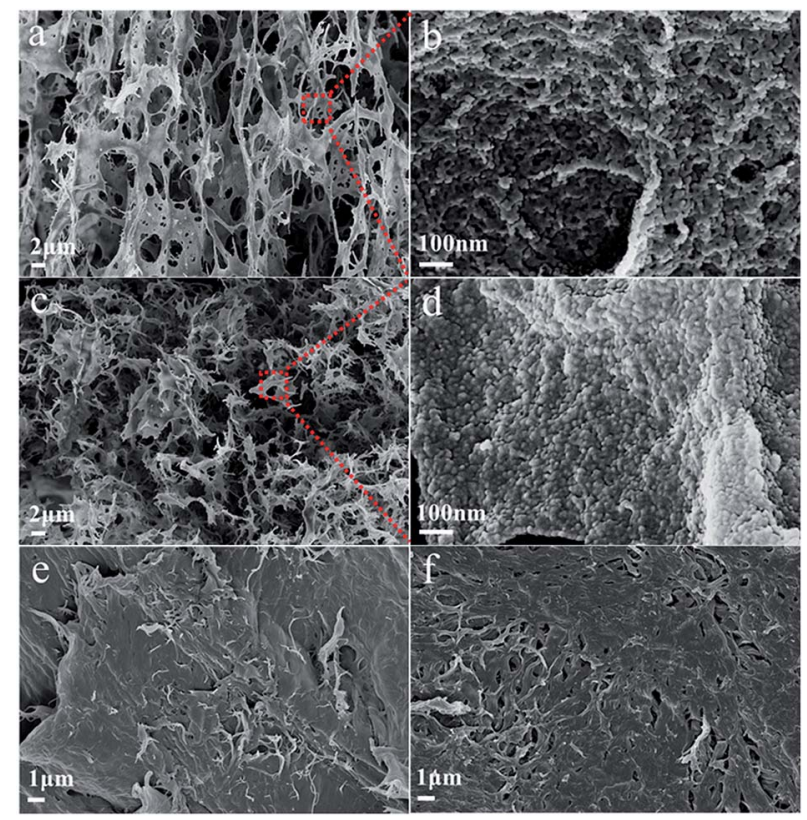

Fig. 3 Structural characterization of chitin-derived carbons: the SEM images of CNC-800 (a and b), CNC-900 (c and d), chitin-800 (e), chitin-900 (f). 


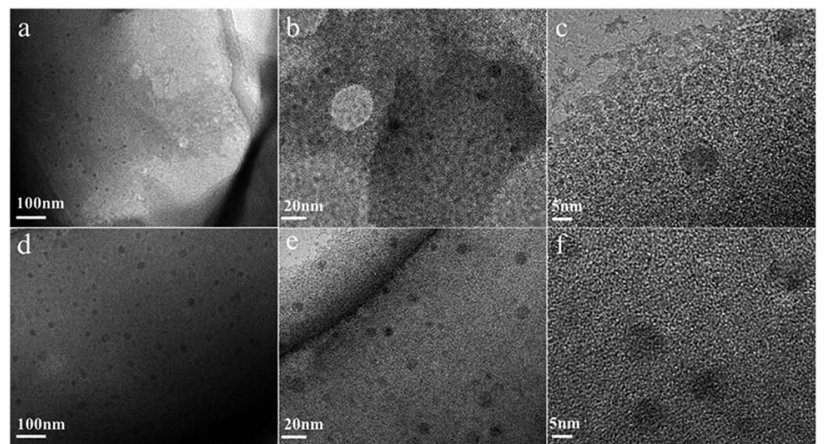

Fig. 4 TEM images of CNC-800 (a) and CNC-900 (d), high-resolution TEM images of CNC-800 (b and c), CNC-900 (e and f).

and CNC-900 with the mean size of $3.3 \mathrm{~nm}$ and $5.4 \mathrm{~nm}$, respectively. The HRTEM micrographs (Fig. $4 \mathrm{c}$ and f) showed the carbon nanosphere had partly graphitized structure with an adjacent interlayer distance of $\sim 0.3 \mathrm{~nm}$.

In order to better understand the detailed pore structure of resultant chitin-derived carbon nanospheres, the nitrogen adsorption/desorption experiments were conducted. According to IUPAC classification, the isotherms of chitin-derived carbon nanospheres corresponded to the Type I, while the isotherms of carbons from raw chitin were the combined Type I and Type IV (Fig. 5a). All the curves exhibited sharp increase in $\mathrm{N}_{2}$ adsorption at relative low pressure $\left(P / P_{0}\right)$, which was caused by the enhanced interaction between adsorbent-adsorbate in the narrow micropores. ${ }^{40}$ The $\mathrm{H} 4$ hysteresis loops were observed in the isotherms of raw chitin-derived carbon at relative pressure in the range of $0.4-0.8$, which were associated with the capillary condensation in mesopores. ${ }^{41}$ In addition, according to the corresponding DFT pore size distribution curves (Fig. 5b), most pores in CNC-800 and CNC-900 felt in the ultramicroporous region (pore size $<0.7 \mathrm{~nm}$ ) and peaked at $0.6 \mathrm{~nm}$, a few pores were in the domain of supermicropores $(0.7-2 \mathrm{~nm})$ and narrow mesopores $(2-4 \mathrm{~nm})$, whereas the chitin-800 and chitin-900 showed large portion of mesopores. Recent study suggests that the existence of ultramicropores $(<0.7 \mathrm{~nm})$ close to the ion size is advantageous for electrochemical performance of carbon..$^{42-44}$ The hydration sheaths could be removed as the solvated ions squeezed through the ultramicropores. ${ }^{42,45}$ As a consequence, the distance from the ion center to the electrode surface was closer, leading to enhanced capacitor performance.
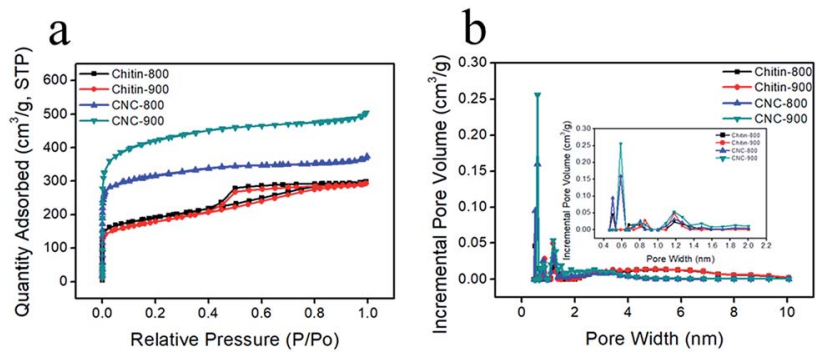

Fig. 5 Nitrogen adsorption/desorption isotherms.
More structural parameters were listed in Table 1. CNC-800 and CNC-900 showed high BET surface areas of $1031 \mathrm{~m}^{2} \mathrm{~g}^{-1}$ and $1363 \mathrm{~m}^{2} \mathrm{~g}^{-1}$, much higher than the carbons derived from the direct carbonization of chitin $\left(626 \mathrm{~m}^{2} \mathrm{~g}^{-1}\right.$ and $600 \mathrm{~m}^{2} \mathrm{~g}^{-1}$ respectively). The high surface area and narrow micropore size distribution of chitin derived carbon nanospheres are beneficial to capacitance performance.

XRD patterns of chitin-derived carbon nanospheres as well as carbons from raw chitin are shown in Fig. 6a. All the XRD patterns showed a broad peak at $\sim 24^{\circ}$ and a weak peak at $\sim 43^{\circ}$, which corresponded to the (002) diffraction and (100) diffraction, ${ }^{5}$ indicating a partly graphitized structure and a disorder phase. ${ }^{21,46}$ This structure feature was also confirmed by Raman spectroscopy (Fig. 6b). The G band at $\sim 1606 \mathrm{~cm}^{-1}$ and $\mathrm{D}$ band at $\sim 1355 \mathrm{~cm}^{-1}$ are associated with the graphitic layers and disordered carbons or defective graphitic structures, respectively. ${ }^{7,43,47}$ The intensity ratio of these two peaks partially depends on the degree of graphitization. ${ }^{19}$ The $I_{\mathrm{D}} / I_{\mathrm{G}}$ ratio for chitin-800, chitin-900, CNC-800, CNC-900 is $0.83,0.81,0.88$, 0.87 , respectively. The slightly increase of $I_{\mathrm{D}} / I_{\mathrm{G}}$ ratios for chitinderived carbon nanospheres suggested the existence of larger amounts of disordered carbon or graphitic defects with a low graphitization degree.

Due to the presence of acetyl amino groups on chitin chains, the calcination of chitin nanogels leads to N-doping in the carbon nanospheres. The full survey spectra of XPS confirmed the existence of $\mathrm{C}, \mathrm{N}$, and $\mathrm{O}$ elements in the resulted carbons (Fig. 6c). High resolution spectrum of $\mathrm{N} 1 \mathrm{~s}$ can be divided into four peaks (Fig. 6d), centered at $397.7 \mathrm{eV}$ (pyridinic N), $398.7 \mathrm{eV}$ (pyrrolic N), $400.6 \mathrm{eV}$ (graphitic N) and $403.5 \mathrm{eV}$ (oxidized-N). ${ }^{19}$ From quantitative analysis in Table 2, we can see the carbons carbonized at $800{ }^{\circ} \mathrm{C}$ possessed more pyridinic and pyrrolic types of nitrogen, which can create defects and electrochemically active sites contributing to the pseudocapacitance contents. ${ }^{19}$ Furthermore, it has been reported that nitrogen doping can enhance the conductivity of the carbon materials and improves the charge transfer property. ${ }^{16}$ The nitrogen doping also increases the wettability of the carbon surface, resulting in improved ion adsorption and increased capacitance. $^{48}$

Cyclic voltammetry (CV) and charge/discharge measurements (GCD) were performed to evaluate the electrochemical characteristics of the obtained chitin-derived carbon nanospheres. Fig. 7a showed the CV curves of different carbons at a scan rate of $20 \mathrm{mV} \mathrm{s}^{-1}$ in $1 \mathrm{M} \mathrm{H}_{2} \mathrm{SO}_{4}$ aqueous electrolyte using a three-electrode system. All the $\mathrm{CV}$ curves displayed quasirectangular shapes, suggesting a typical electrical double layer capacitive behavior. Slight humps occurred due to the pseudocapacitance provide by the doped nitrogen. The integrated area of the rectangles for CNCs was larger than the carbons from raw chitin (chitin-900 < chitin-800 < CNC-900 < CNC-800), indicating higher capacitance of the carbon nanospheres, which may be related to more defects and larger specific surface area. Fig. 7b showed the GCD curves of different carbons at a current density of $1 \mathrm{~A} \mathrm{~g}^{-1}$. The GCD curves presented almost symmetrical triangles with slight tilts, confirming the good capacitive performance and a small fraction of pseudocapacitance nature. 
Table 1 Surface area and porous size distribution

\begin{tabular}{llllll}
\hline Sample & $S_{\text {BET }}\left(\mathrm{m}^{2} \mathrm{~g}^{-1}\right)$ & $S_{\text {micro }}\left(\mathrm{m}^{2} \mathrm{~g}^{-1}\right)$ & $V_{\text {total }}\left(\mathrm{cm}^{3} \mathrm{~g}^{-1}\right)$ & $V_{\text {micro }}\left(\mathrm{cm}^{3} \mathrm{~g}^{-1}\right)$ & $V_{\text {meso }}\left(\mathrm{cm}^{3} \mathrm{~g}^{-1}\right)$ \\
\hline Chitin-800 & 626 & 312 & 0.46 & 0.16 & 0.30 \\
Chitin-900 & 600 & 262 & 0.45 & 0.13 & 0.32 \\
CNC-800 & 1031 & 706 & 0.57 & 0.35 & 0.22 \\
CNC-900 & 1363 & 877 & 0.78 & 0.44 & 0.34
\end{tabular}
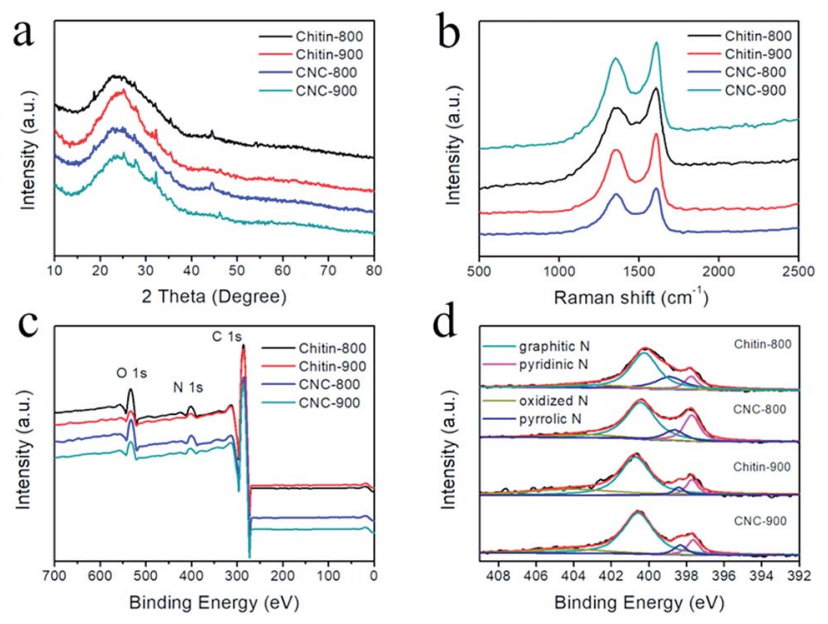

Fig. 6 The structural characterization: XRD patterns (a), Raman spectra (b), full-scale XPS spectra (c), high-resolution N 1s spectra (d).

Table 2 Atomic content and percentage of different types of nitrogen based on XPS survey spectra

\begin{tabular}{lccclrrr}
\hline & & \multicolumn{5}{c}{$\%$ of total N 1s } \\
\cline { 5 - 8 } Samples & C\% & O\% & N\% & N-Q & N-5 & N-6 & Oxidized-N \\
\hline Chitin-800 & 88.3 & 7.6 & 4.1 & 57.8 & 9.5 & 20.8 & 11.9 \\
Chitin-900 & 93.9 & 4.4 & 1.7 & 58.7 & 4.3 & 9.3 & 27.7 \\
CNC-800 & 91.5 & 5.3 & 3.2 & 57 & 11.8 & 21.5 & 9.7 \\
CNC-900 & 95.6 & 2.8 & 1.6 & 66.5 & 7.2 & 9.8 & 16.5
\end{tabular}

The specific capacitance values from GCD curves were shown in Fig. 7c. CNC-800 exhibited superior specific capacitance of $192 \mathrm{~F}$ $\mathrm{g}^{-1}$ at $0.5 \mathrm{~A} \mathrm{~g}^{-1}, 179 \mathrm{~F} \mathrm{~g}^{-1}$ at $1 \mathrm{~A} \mathrm{~g}^{-1}$, which was comparable to several previously reported bio-carbons but lower than polymer precursor-derived carbons (Table 3)..$^{6,39,49-52}$ This may be caused by a more optimal structure and higher nitrogen content for polymer precursor-derived carbons. When the current density increased to $10 \mathrm{~A} \mathrm{~g}^{-1}$, the specific capacitance decreased to $155 \mathrm{~A} \mathrm{~g}^{-1}$ in virtue of the diffusion limitation of ions during fast charging-discharging, ${ }^{53}$ with capacitance retention of $81 \%$, indicating good rate capability.

EIS measurements (Fig. 7d) were also conducted to further investigate the conductivity and ion transfer. The Nyquist plots consist of a semicircle in the high frequency range and a straight line in the low frequency range. The intercept of the semicircle with the real axis represents the equivalent series resistance (ESR), including the resistance of the electrolyte $\left(R_{\mathrm{S}}\right)$,
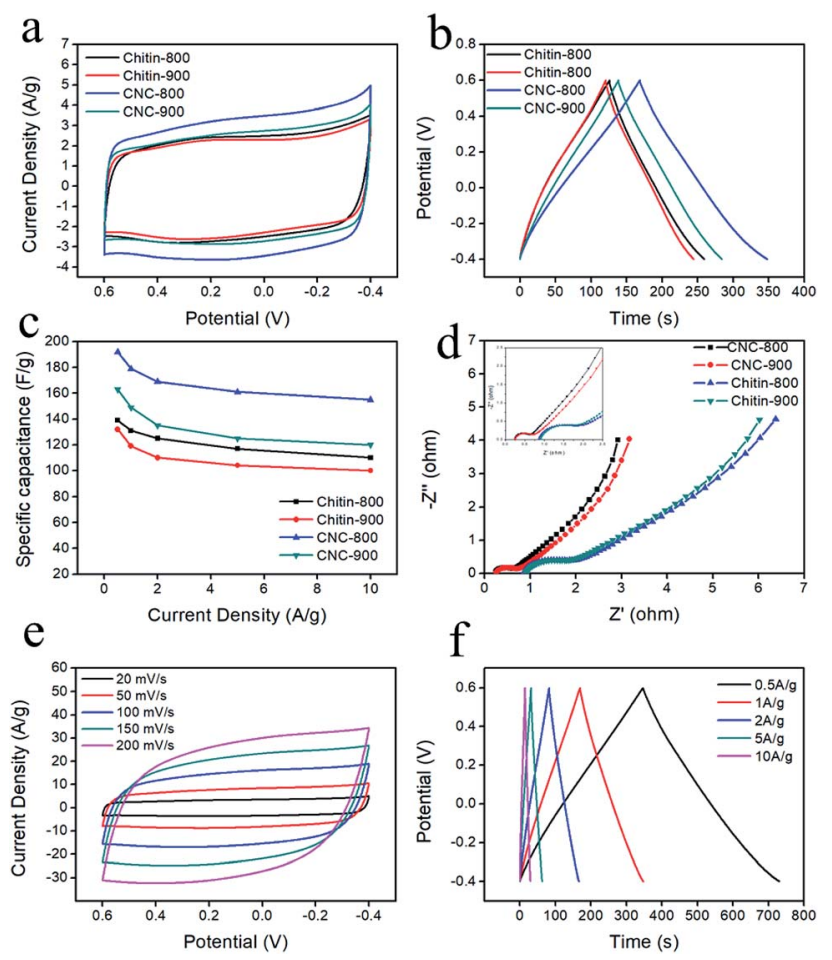

Fig. $7 \mathrm{CV}$ curves (a) of carbons at a scan rate of $20 \mathrm{mV} \mathrm{s}^{-1}$; galvanostatic charge/discharge curves (b) at a current density of $1 \mathrm{~A} \mathrm{~g}^{-1}$; specific capacitance versus current density (c); EIS analysis (d); CV curves (e) of $\mathrm{CNC}-800$ at different scan rates in $1 \mathrm{M} \mathrm{H}_{2} \mathrm{SO}_{4}$ aqueous solution; galvanostatic charge/discharge curves (f) at different current densities.

the internal electrode resistance and the contact resistance between the electrode and current collector, ${ }^{\mathbf{8} 42}$ among which the electrolyte resistance $\left(R_{\mathrm{S}}\right)$ is the dominant part. ${ }^{54}$ The $R_{\mathrm{S}}$ values of chitin-900, chitin-800, CNC-800, CNC-900 were 0.93, $0.86,0.25$ and $0.26 \Omega$, respectively, indicating that the carbon nanospheres have low resistance and high conductivity. The diameter of semicircle refers to the interfacial charge transfer resistance $\left(R_{\mathrm{ct}}\right),{ }^{55}$ the $\mathrm{CNC}-800$ and $\mathrm{CNC}-900$ have smaller semicircle diameters, revealing a rapid charge transference. CNC-800 was further characterized with CV at different scan rates and GCD at various current densities. As shown in Fig. 7e and $\mathrm{f}$, the curves all exhibited ideal shapes, indicating good capacitive characteristic and electrochemical reversibility.

In order to further evaluate the applicability of the chitin derived carbon nanospheres, the electrochemical performance of CNC-800 was tested with a symmetrical two-electrode cell both in aqueous and organic electrolytes. Fig. 8a showed the CV 
Table 3 Comparison of specific capacitance of different carbon materials from recent literature

\begin{tabular}{|c|c|c|c|c|}
\hline Material & Precursor & $\begin{array}{l}\text { Capacitance at } \\
1 \mathrm{~A} \mathrm{~g}^{-1}\left(\mathrm{~F} \mathrm{~g}^{-1}\right)\end{array}$ & Electrolyte & Ref. \\
\hline $\mathrm{N}$-doped carbon nanospheres & $\begin{array}{l}\text { Melamine-phenolic-formaldehyde (MPF) } \\
\text { resin }\end{array}$ & 432 & $6 \mathrm{M} \mathrm{KOH}$ & 39 \\
\hline Hierarchical N-doped porous carbon & Endothelium corneum gigeriae galli & 198 & $6 \mathrm{M} \mathrm{KOH}$ & 49 \\
\hline Sulfur and nitrogen dual-doping carbon & Shell of broad beans & 174 & $6 \mathrm{M} \mathrm{KOH}$ & 6 \\
\hline $\mathrm{N}$-doped carbon double-shell nanoparticles & Polydopamine & 184 & $1 \mathrm{M} \mathrm{H}_{2} \mathrm{SO}_{4}$ & 50 \\
\hline N-doped microporous carbon nanospheres & Chitin & 179 & $1 \mathrm{M} \mathrm{H}_{2} \mathrm{SO}_{4}$ & Our work \\
\hline
\end{tabular}
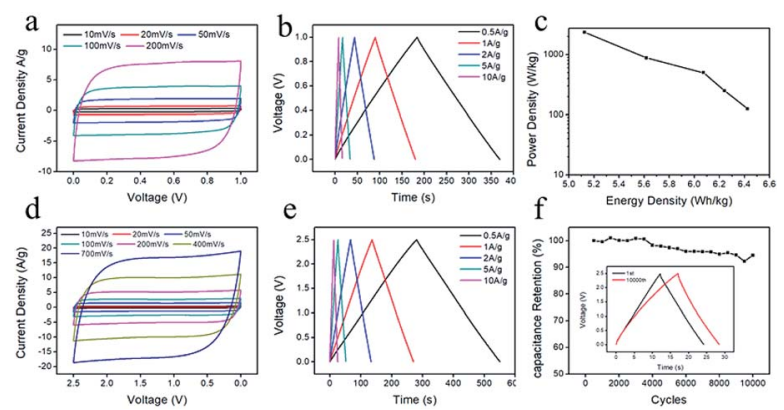

Fig. 8 CV curves (a) at different scan rates, galvanostatic charge/ discharge curves (b) at different current densities, Ragone plots (c) of CNC-800 in symmetrical two-electrode cell in $1 \mathrm{M} \mathrm{H}_{2} \mathrm{SO}_{4}$ aqueous solution; CV curves (d) at different scan rates, galvanostatic charge/ discharge curves (e) at different current densities, cycling stabilities at galvanostatic current density of $10 \mathrm{~A} \mathrm{~g}^{-1}$ for 10000 cycles (f) of CNC800 in symmetrical two-electrode cell in $1 \mathrm{M} \mathrm{TEABF}_{4}-\mathrm{AN}$.

curves of the aqueous device, which presented perfect symmetrical rectangular shapes even under a high scan rate, indicating a high rate capability. The GCD curves (Fig. 8b) also maintained symmetric triangular shapes at all current densities. The specific capacitance at current density of $1 \mathrm{~A} \mathrm{~g}^{-1}$ was $180 \mathrm{~F} \mathrm{~g}^{-1}$, being comparable to that in three-electrode system. Ragone plot was recorded in Fig. 8c. The energy density and power density were calculated from the GCD curves. The maximal energy density was $6.4 \mathrm{~W} \mathrm{~h} \mathrm{~kg}^{-1}$ at a power density of $125 \mathrm{~W} \mathrm{~kg}^{-1}$, while the energy density remained as high as $5.1 \mathrm{~W} \mathrm{~h} \mathrm{~kg}^{-1}$ with a power density of $2364.9 \mathrm{~W} \mathrm{~kg}^{-1}$, indicating good energy storage property and fast charge/discharge performance. Fig. 8d illustrated the $\mathrm{CV}$ curves of organic device. Interestingly, the $\mathrm{CV}$ curves still maintained rectangularlike shapes as the scan rate increased to $700 \mathrm{mV} \mathrm{s}^{-1}$. The specific capacitance from Fig. 8e was $107 \mathrm{~F} \mathrm{~g}^{-1}$ at current density of $1 \mathrm{~A} \mathrm{~g}^{-1}$. The energy density in organic electrolyte was $23.4 \mathrm{~W} \mathrm{~h} \mathrm{~kg}{ }^{-1}$ with a power density of $313.9 \mathrm{~W} \mathrm{~kg}^{-1}$, $20.6 \mathrm{~W} \mathrm{~h} \mathrm{~kg}^{-1}$ with a power density of $6035.6 \mathrm{~W} \mathrm{~kg}^{-1}$, which was comparable with other literature..$^{56-58}$ And as shown in Fig. 8f, the capacitance retention still retained $95 \%$ after 10000 cycles at high current density of $10 \mathrm{~A} \mathrm{~g}^{-1}$, manifesting an outstanding cycling stability. The advanced performance of CNC-800 in both organic and aqueous electrolytes confirms the versatile applicability of chitin derived carbon nanospheres for energy storage.

\section{Conclusion}

In summary, N-doped carbon nanospheres with ordered microporous structure were fabricated from chitin nanogels. The nanospheres had a diameter of $20-30 \mathrm{~nm}$ and demonstrated large BET surface area of $1363 \mathrm{~m}^{2} \mathrm{~g}^{-1}$. CNC-800 showed high electrochemical capacitance of $192 \mathrm{~F} \mathrm{~g}^{-1}$ at $0.5 \mathrm{~A} \mathrm{~g}^{-1}$ in $1 \mathrm{M} \mathrm{H}_{2} \mathrm{SO}_{4}$ and $107 \mathrm{~F} \mathrm{~g}^{-1}$ in $1 \mathrm{M} \mathrm{TEABF}_{4}$-AN organic electrolyte. Moreover, CNC800 showed outstanding cycling stability over 10000 cycles and good retention capability of $95 \%$ at a current density of $10 \mathrm{~A} \mathrm{~g}^{-1}$. Therefore, the facile preparation $\mathrm{N}$-doped carbon nanospheres with outstanding capability provides a novel method to construct attractive energy storage materials from chitin wastes.

\section{Conflicts of interest}

There are no conflicts to declare.

\section{Acknowledgements}

This work was supported by National Natural Science Foundation of China (51373124, 21334005), Fundamental Research Funds for the Central Universities (2042016kf0145), Natural Science Foundation of Hubei Province of China (Team Project, No. 2015CFA017).

\section{Notes and references}

1 B. Shan, Y. Cui, W. Liu, Y. Zhang, S. Liu, H. Wang, L. Sun, Z. Wang and R. Wu, ACS Sustainable Chem. Eng., 2018, 6, 14989-15000.

2 C. X. Guo and C. M. Li, Energy Environ. Sci., 2011, 4, 45044507.

3 J. Deng, T. Y. Xiong, F. Xu, M. M. Li, C. L. Han, Y. T. Gong, H. Y. Wang and Y. Wang, Green Chem., 2015, 17, 4053-4060. 4 G. P. Xiong, P. G. He, Z. P. Lyu, T. F. Chen, B. Y. Huang, L. Chen and T. S. Fisher, Nat. Commun., 2018, 9, 790.

5 E. Hao, W. Liu, S. Liu, Y. Zhang, H. Wang, S. Chen, F. Cheng, S. Zhao and H. Yang, J. Mater. Chem. A, 2017, 5, 2204-2214. 6 G. Xu, J. Han, B. Ding, P. Nie, J. Pan, H. Dou, H. Li and X. Zhang, Green Chem., 2015, 17, 1668-1674.

7 Y. Guo, W. Liu, R. Wu, L. Sun, Y. Zhang, Y. Cui, S. Liu, H. Wang and B. Shan, ACS Appl. Mater. Interfaces, 2018, 10, 38376-38386. 
8 B. H. Lu, L. Y. Hu, H. Y. Yin, W. Xiao and D. H. Wang, $R S C$ Adv., 2016, 6, 106485-106490.

9 Y. X. Wang, J. Q. Yang, R. B. Du and L. Y. Chen, ACS Appl. Mater. Interfaces, 2017, 9, 23731-23740.

10 C. Wang, X. F. Wang, H. Lu, H. L. Li and X. S. Zhao, Carbon, 2018, 140, 139-147.

11 L. F. Chen, Z. H. Huang, H. W. Liang, W. T. Yao, Z. Y. Yu and S. H. Yu, Energy Environ. Sci., 2013, 6, 3331-3338.

12 C. L. Long, D. P. Qi, T. Wei, J. Yan, L. L. Jiang and Z. J. Fan, Adv. Funct. Mater., 2014, 24, 3953-3961.

13 Y. Yang, R. C. Sun and X. H. Wang, Mater. Lett., 2017, 189, 248-251.

14 Q. H. Bai, Q. C. Xiong, C. Li, Y. H. Shen and H. Uyama, Appl. Surf. Sci., 2018, 455, 795-807.

15 Z. Q. Ye, F. J. Wang, C. Jia and Z. Q. Shao, J. Mater. Sci., 2018, 53, 12374-12387.

16 C. J. Raj, M. Rajesh, R. Manikandan, K. H. Yu, J. R. Anusha, J. H. Ahn, D. W. Kim, S. Y. Park and B. C. Kim, J. Power Sources, 2018, 386, 66-76.

17 T. D. Nguyen, K. E. Shopsowitz and M. J. MacLachlan, J. Mater. Chem. A, 2014, 2, 5915-5921.

18 B. B. Ding, S. S. Huang, K. Pang, Y. X. Duan and J. M. Zhang, ACS Sustainable Chem. Eng., 2018, 6, 177-185.

19 B. Duan, X. Gao, X. Yao, Y. Fang, L. Huang, J. Zhou and L. N. Zhang, Nano Energy, 2016, 27, 482-491.

20 J. You, M. J. Li, B. B. Ding, X. C. Wu and C. X. Li, Adv. Mater., 2017, 29, 1606895.

21 J. Zhou, L. Bao, S. J. Wu, W. Yang and H. Wang, Carbohydr. Polym., 2017, 173, 321-329.

22 L. Gao, L. Xiong, D. Xu, J. Cai, L. Huang, J. Zhou and L. Zhang, ACS Appl. Mater. Interfaces, 2018, 10, 28918-28927.

23 A. Chen, Y. Yu, T. Xing, R. Wang, Y. Zhang and Q. Li, J. Mater. Sci., 2015, 50, 5578-5582.

24 D. Guo, X. a. Chen, Z. Fang, Y. He, C. Zheng, Z. Yang, K. Yang, Y. Chen and S. Huang, Electrochim. Acta, 2015, 176, 207-214.

25 Q. Zhang, L. Li, Y. Wang, Y. Chen, F. He, S. Gai and P. Yang, Electrochim. Acta, 2015, 176, 542-547.

26 M. H. Naveen, K. Shim, M. S. A. Hossain, J. H. Kim and Y.-B. Shim, Adv. Energy Mater., 2017, 7, 1602002.

27 S. Liu, Y. Cai, X. Zhao, Y. Liang, M. Zheng, H. Hu, H. Dong, S. Jiang, Y. Liu and Y. Xiao, J. Power Sources, 2017, 360, 373382.

28 S.-K. Kim, E. Jung, M. D. Goodman, K. S. Schweizer, N. Tatsuda, K. Yano and P. V. Braun, ACS Appl. Mater. Interfaces, 2015, 7, 9128-9133.

29 J. Liu, T. Y. Yang, D. W. Wang, G. Q. M. Lu, D. Y. Zhao and S. Z. Qiao, Nat. Commun., 2013, 4, 2798.

30 Z. Lei, N. Christov and X. S. Zhao, Energy Environ. Sci., 2011, 4, 1866-1873.

31 Y. Fang, D. Gu, Y. Zou, Z. X. Wu, F. Y. Li, R. C. Che, Y. H. Deng, B. Tu and D. Y. Zhao, Angew. Chem., Int. Ed., 2010, 49, 7987-7991.

32 Z. B. Wang, H. W. Qiang, Z. H. Zhu, J. P. Liu, C. N. Chen and D. W. Zhang, ChemElectroChem, 2018, 5, 2242-2249.
33 S. E. Bae, K. J. Kim, I. H. Choi and S. Huh, Carbon, 2016, 99, 8-16.

34 G. Wang, Y. H. Sun, D. B. Li, H. W. Liang, R. H. Dong, X. L. Feng and K. Mullen, Angew. Chem., Int. Ed., 2015, 54, 15191-15196.

35 B. Duan, C. Y. Chang, B. B. Ding, J. Cai, M. Xu, S. C. Feng, J. Z. Ren, X. W. Shi, Y. M. Du and L. N. Zhang, J. Mater. Chem. A, 2013, 1, 1867-1874.

36 B. Duan, X. Zheng, Z. Xia, X. Fan, L. Guo, J. Liu, Y. Wang, Q. Ye and L. Zhang, Angew. Chem., Int. Ed., 2015, 54, 51525156.

37 J. Zhao, H. Lai, Z. Lyu, Y. Jiang, K. Xie, X. Wang, Q. Wu, L. Yang, Z. Jin, Y. Ma, J. Liu and Z. Hu, Adv. Mater., 2015, 27, 3541-3545.

38 F. Sun, Z. Qu, J. Gao, H. B. Wu, F. Liu, R. Han, L. Wang, T. Pei, G. Zhao and Y. Lu, Adv. Funct. Mater., 2018, 28, 1804190.

39 F. Sun, J. Gao, X. Pi, L. Wang, Y. Yang, Z. Qu and S. Wu, J. Power Sources, 2017, 337, 189-196.

40 M. Thommes, K. Kaneko, A. V. Neimark, J. P. Olivier, F. Rodriguez-Reinoso, J. Rouquerol and K. S. W. Sing, Pure Appl. Chem., 2015, 87, 1051-1069.

41 Y. Gao, W. Zhang, Q. Yue, B. Gao, Y. Sun, J. Kong and P. Zhao, J. Power Sources, 2014, 270, 403-410.

42 A. Ghosh and Y. H. Lee, ChemSusChem, 2012, 5, 480-499.

43 J. S. Zhou, J. Lian, L. Hou, J. C. Zhang, H. Y. Gou, M. R. Xia, Y. F. Zhao, T. A. Strobel, L. Tao and F. M. Gao, Nat. Commun., 2015, 6, 8503.

44 J. Chmiola, C. Largeot, P. L. Taberna, P. Simon and Y. Gogotsi, Angew. Chem., Int. Ed., 2008, 47, 3392-3395.

45 C. Vix-Guterl, E. Frackowiak, K. Jurewicz, M. Friebe, J. Parmentier and F. Beguin, Carbon, 2005, 43, 1293-1302.

46 B. Lu, J. Zhou, Y. Song, H. Wang, W. Xiao and D. Wang, Faraday Discuss., 2016, 190, 147.

47 F. C. Zheng, Y. Yang and Q. W. Chen, Nat. Commun., 2014, 5, 5261.

48 Y. Deng, Y. Xie, K. Zou and X. Ji, J. Mater. Chem. A, 2016, 4, 1144-1173.

49 X. Hong, K. S. Hui, Z. Zeng, K. N. Hui, L. Zhang, M. Mo and M. Li, Electrochim. Acta, 2014, 130, 464-469.

50 J. Yun, J. Jun, J. Lee, J. Ryu, K. Lee, H. Yu and J. Jang, RSC Adv. , 2017, 7, 20694-20699.

51 B. Kishore, D. Shanmughasundaram, T. R. Penki and N. Munichandraiah, J. Appl. Electrochem., 2014, 44, 903-916.

52 H. Qu, X. Zhang, J. Zhan, W. Sun, Z. Si and H. Chen, ACS Sustainable Chem. Eng., 2018, 6, 7380-7389.

53 B. H. Lu, L. Y. Hu, H. Y. Yin, X. H. Mao, W. Xiao and D. H. Wang, Int. J. Hydrogen Energy, 2016, 41, 18713-18720. 54 Z. Li Li and X. S. Zhao, Chem. Soc. Rev., 2009, 38, 2520-2531. 55 S. Biswas and L. T. Drzal, Chem. Mater., 2010, 22, 5667-5671. 56 F. Sun, H. Wu, X. Liu, F. Liu, H. Zhou, J. Gao and Y. Lu, Nano Res., 2016, 9, 3209-3221.

57 X. M. Fan, C. Yu, J. Yang, Z. Ling, C. Hu, M. D. Zhang and J. S. Qiu, Adv. Energy Mater., 2015, 5, 7.

58 Z. Lu, C. Hui, S. Zhu, L. Hou and C. Yuan, Green Chem., 2015, 17, 2373-2382. 